\title{
PERSPECTIVAS DE FUTURO \\ EN HISTORIA ECONÓMICA
}

SEBASTIÁN COLL

Universidad de Cantabria

\section{RESUMEN}

Este artículo explora posibles vías de evolución de la historia económica en un futuro próximo. El autor pasa revista a la trayectoria de la disciplina durante las últimas décadas, con especial atención a la influencia de la revolución cliométrica, y argumenta que la historia económica pasa actualmente por una situación crítica. Para salir de ella, aboga por una mayor atención al cambio tecnológico y al cambio institucional, como temas distintivos del largo plazo, estrechando la cooperación con la economía del desarrollo, la economía del crecimiento, la economía neoinstitucional, la economía de la empresa y la economía del cambio tecnológico.

\section{ABSTRACT}

This article explores possible ways in which economic history may evolve in the foreseeable future. The author starts with a review of the evolution of the discipline in past decades, with especial attention to the influx of the cliometric revolution, and contends that the economic history is presently passing through a critical situation. To overcome it, the author makes a plea for increasing attention towards economic and institutional change, seen as topics distinctive of the long run, and for a rapprochement to development economics, growth economics, neo-institutional economics, firm theory and economics of technical change. 


\section{INTRODUCCIÓN}

Las páginas que siguen se escribieron originalmente en 1998 para el Curso «Nuevas tendencias en Historia Económica. Una perspectiva internacional», organizado por los profesores Reher y Hernández Andreu en el marco de los Cursos de Verano de la Universidad Complutense y de los actos preparatorios del XII Congreso Internacional de Historia Económica. En esa ocasión, los organizadores me asignaron la paralizante responsabilidad de hablar del futuro de la historia económica en presencia de especialistas de la categoría del profesor Robert Fogel, el cual, para desilusión de todos aunque no sin cierto alivio culpable por mi parte, canceló finalmente su compromiso por motivos de salud.

Aunque en una primera impresión la invitación de los organizadores denotaba una conmovedora confianza en mi limitada capacidad, también me hacía sospechar una posible segunda intención por su parte. Entre mis pecados de juventud -cuyo recuerdo evoqué para infundirme valor en el trance - se cuenta la lectura de un manual para agitadores, una parte del cual estaba dedicado a algo que podríamos llamar «cómo manipular a otros». El libro lo explicaba por medio de la siguiente (y brillante) ilustración: «¿Cómo conseguir que un gato coma pimienta?». La respuesta era: «Ponga usted pimienta sobre la cesta del gato; cuando éste se acueste, la pimienta le picará en la piel, se lamerá... y se la tragará.» Recordando el episodio, me asaltó la idea de que los organizadores del curso -más o menos de mi misma generación - probablemente habían leído el mismo manual, y de que yo estaba haciendo el papel de pimienta en la cesta de nuestros distinguidos huéspedes, verbigracia en la del profesor Fogel: demasiado famosos como para imponerles un tema de disertación, la manera de hacerles hablar del futuro de la historia económica sería someter a prueba su paciencia, poniendo a cualquier otro a desbarrar delante de ellos.

La convicción de estar desempeñando un rol secundario alivió mi miedo escénico, permitiéndome poner por escrito algunas ideas. Por ausencia de Robert Fogel, sin embargo, mi intervención pasó del papel de agente provocador a otro de mayor protagonismo. Pasado un tiempo, uno de los organizadores del curso de El Escorial me animó a someter lo que entonces escribí al proceso de selección de artículos de la Revista de Historia Económica, cuyos árbitros resultaron ser tan indulgentes como lo habían sido dichos organizadores o el público asistente al curso... supongo que con la misma doble intención de provocar un debate sobre el tema en las 
páginas de la Revista. Dicho lo anterior, sólo me resta hacer un breve comentario relativo al título del artículo. Como saben los lectores, la autocorrelación es un fenómeno frecuente en series temporales. Lo que quiero decir con ello es que, hasta donde llega la vista, la historia económica futura seguramente se parecerá mucho a la actual. Por supuesto, algunas tendencias actuales se reforzarán, otras se debilitarán, y aparecerán algunas nuevas. Supongo que lo que se espera de mí es que identifique discontinuidades, más que las (esperables) continuidades del proceso. Desde luego, trataré de hacerlo, pero sin traicionar mi convicción de que, en estos terrenos, las cosas se mueven con lentitud.

\section{EL PASADO RECIENTE DE LA HISTORIA ECONÓMICA}

Hablar de discontinuidades nos lleva a examinar brevemente el presente, o, mejor, el pasado reciente de nuestra disciplina. Dejando margen para peculiaridades nacionales, esta revisión al estado actual de la historia económica debe empezar con un reconocimiento de la victoria, aunque parcial, de aquello que en su día se llamó la Nueva Historia Económica (NEH en lo sucesivo). Éste es casi un lugar común, de manera que, al visitarlo, simplemente me pongo a la larga cola de los autores que lo han hecho antes que yo ${ }^{1}$. Desde luego, esa victoria fue más completa y temprana en los Estados Unidos que en Europa: en comparación con los más antiguos logros de la cliometría en ese primer país, la fundación de la Sociedad Europea de Economía Histórica en 1991 constituye un éxito tardío, aunque no por ello deja de ser significativa. En cuanto a España, hace diez años publiqué un ensayo sobre La Nueva Historia Económica $y$ su influencia en España. No hace mucho, mi editor de entonces me propuso que escribiese una versión actualizada; sin embargo, un rápido repaso mental al número de trabajos más o menos «cliométricos» publicados durante los noventa me bastó para darme cuenta de la magnitud de la tarea, y para declinar la invitación.

En el fondo, no me siento muy a gusto al hablar de triunfo de la cliometría, y supongo que a muchos lectores les pasará lo mismo. Ahora que están hechas las paces y que el tratado (tácito) establece concesiones por ambas partes, no apetece entrar en quién ganó la guerra. Al pendenciero Robert Fogel de los años sesenta le sustituyó otro más conciliador, o, como

\footnotetext{
'Entre otros, McCloskey (1987), Field (1987), Whaples (1991) y Dumke (1992).
} 
Field (1987) expresó de manera rotunda, hoy en día la revolución cliométrica está muerta, precisamente porque triunfó. Lo que quiere esto decir es que los trabajos «cliométricos» no han barrido a aquellos que no lo son. Más bien lo que ha pasado es que la cliometría ha permeado más o menos la historia económica en general, haciendo más frecuente el uso de la teoría económica y de las herramientas estadísticas. Con ello, los trabajos actuales de historia económica van desde aquellos que son cliometría en estado puro hasta los puramente «no cliométricos», con numerosas tonalidades intermedias. Es indudable que una parte de las aspiraciones iniciales de la NHE se ha perdido por el camino - así, el énfasis en los contrafactuales o las pretensiones de efectuar siempre contrastaciones estadísticas y enunciar líneas de causación sin espacio para la ambigüedad-, aunque tal pérdida quizá no sea muy de lamentar, visto lo que se ha ganado a cambio:

Para empezar, ha sido posible ampliar sustancialmente el estrecho territorio de la NHE original, tanto en el tiempo como en el espacio. Afortunadamente, hoy estamos lejos de los tiempos en los que se pensaba que la NHE nunca llegaría a cruzar las fronteras de la historia económica reciente de los Estados Unidos ${ }^{2}$, expectativa que recibió un temprano mentís con la impresionante contribución de North y Thomas (1973). Por lo que respecta al otro símbolo viviente de la NHE - me refiero, por supuesto, a Robert Fogel-, sus «reflexiones sobre la desaparición del hambre en Europa» no tienen evidentemente nada que ver ni con el pasado reciente ni con los Estados Unidos. Otro cargo antiguo contra la NHE fue su olvido de las cuestiones distributivas, sacrificadas en aras del dios Crecimiento. Sin embargo, la distribución de la renta y de la riqueza se convirtió en uno de los temas de moda en las revistas «cliométricas» durante los años ochenta, y no ha dejado de estar de moda desde entonces.

Comoquiera que el desarrollo de las instituciones económicas estaba en el centro de las preocupaciones de la historia económica tradicional, también se pensó en su momento que la NHE había abandonado su estudio, remplazándolo por una confianza ilimitada en el funcionamiento universal de las leyes del mercado ${ }^{3}$. En realidad, tal impresión se llevaba mal con el temprano interés de la NHE hacia el análisis económico de la esclavitud en el sur de los Estados Unidos, y es que el conflicto aparente entre la NHE y la historia de las instituciones no pasaba en el fondo

\footnotetext{
2 Ésa era, por ejemplo, la opinión de Hughes (1971).

Véase Redlich (1965), p. 482 y Field (1987), p. 3.
} 
de reflejar el existente entre economía ortodoxa e institucionalismo. De la misma manera que este último conflicto no impidió el surgimiento de una potente «economía neoinstitucional», o «economía institucional neoclásica», hoy en día existe una poderosa corriente neoinstitucional en aguas de la cliometría, tanto que a esta última se le ha visto flirtear con la historia política y aun con la historia militar. Por supuesto, este último fenómeno se ha acompañado de una reducción del énfasis en la cuantificación y en el uso de las herramientas estadísticas. Hoy en día, estas últimas se siguen viendo como instrumentos potentes con vistas a la contrastación de hipótesis, que conviene usar siempre que sea posible. Pero cuando no lo sea, la mayor parte de los cliómetras coincide en que la falta de esos instrumentos no debe alejarnos del estudio de cuestiones que, por lo demás, resultan interesantes.

Esta relación que acabo de hacer puede interpretarse como una enumeración tanto de las conquistas como de las concesiones hechas por la cliometría frente a otras formas más antiguas de hacer historia económica. Abarcándolas a todas, existe también un reconocimiento, por parte de la NHE, de la utilidad de la historia tradicional, siempre que esté bien hecha ${ }^{4}$. Es más, determinados cliómetras han postulado una revalorización de la historia tradicional: así, para Field (1987), la simple descripción de las variables, tanto endógenas como exógenas -incluyendo a aquellas que no son susceptibles de cuantificación-, constituye un requisito para dotar de sentido al análisis económico; en la medida en que éste es el dominio de la historia «tradicional», la cliometría no puede prescindir de ella, ni tiene el menor derecho a mostrarse desdeñosa con ella.

Desde luego, no todos los avances de la historia económica a lo largo de las últimas décadas han venido de la mano de la revolución cliométrica, pero existe un amplio consenso en el sentido de que muchos de ellos sí lo han hecho. Tres campos en particular han recibido esa lluvia fertilizadora: la contrastación de hipótesis, la reconstrucción de cuentas nacionales y la formulación (o reformulación) de respuestas a viejas preguntas. Creo que merece la pena dedicar algún espacio al examen de algunas muestras de los tres tipos, como ilustración de estas afirmaciones. Por supuesto, no voy a tratar de dibujar unos panoramas detallados, pero la cita de unos pocos ejemplos puede resultar de utilidad.

En el fondo, no hay muchos casos en los cuales el uso de teoría económica y/o instrumentos estadísticos haya cerrado un debate de una vez

\footnotetext{
+ Véase Fogel (1975), p. 350, para una ilustración de este punto.
} 
para siempre. De hecho, bastantes menos casos de los que uno imaginaría a la vista de las pretensiones originales de la $\mathrm{NEH}$ de la primera hora. Por ello, voy a referirme a un caso clásico, como es el análisis económico de la esclavitud en el sur de los Estados Unidos antes de la guerra civil americana. Como los lectores conocen, una pregunta importante en relación con la esclavitud sureña alude a su rentabilidad. Si el empleo de mano de obra esclava resultaba no ser rentable en vísperas de la guerra civil, entonces es lógico pensar que la esclavitud se habría extinguido sola, y que el baño de sangre de la guerra podría haberse evitado. Las heridas causadas por las guerras civiles siguen doliendo durante mucho tiempo después de que esas guerras se hayan acabado, y en los países que las han sufrido es corriente que se susciten debates acerca de si fueron o no evitables. En el caso norteamericano, la respuesta a esta pregunta universal pasaba por una correcta caracterización de la mano de obra esclava. Conrad y Meyer (1958) se dieron cuenta de que un esclavo era un bien de capital, de manera que su rentabilidad debía establecerse como se hace en el caso de otros bienes de capital: a saber, comparando su rédito con su coste de oportunidad, esto es, con el rédito de otras formas de inversión de riesgo y plazo comparables. De acuerdo con los resultados de estos autores, el empleo de esclavos en la agricultura del Sur era rentable, de manera que no se veían perspectivas para una desaparición autónoma de la esclavitud. Las investigaciones posteriores llevadas a cabo por Yasuba (1961), Fogel y Engerman (1974) y muchos otros han venido a confirmar básicamente esta conclusión fundamental.

Pasando ahora a nuestro segundo tema, la reconstrucción de series de los grandes agregados económicos ha consumido enormes cantidades del esfuerzo e imaginación de los cliómetras de cualquier país. Mientras que esta reconstrucción se lleva bien con la insistencia que éstos ponen en la cuantificación y en el análisis formalizado, el uso que hacen de la teoría les permite identificar sustitutivos adecuados o formas de estimación para aquellas variables sobre las cuales falta información. En el caso norteamericano, esta tarea ha sido (más o menos) completada en las décadas pasadas, de manera que los cliómetras de esta nacionalidad se encuentran hoy en día relevados de la misma y en condiciones de canalizar sus energías hacia otros temas. En países como España, sin embargo, estamos aún en plena faena. Por ello, y a modo de compensación por el carácter a menudo frustrante de este tipo de trabajo, espero se me perdonará si empleo un ejemplo español y hablo en primera persona. 
La reconstrucción del PIB español del siglo xIx tropieza con el obstáculo de la producción agrícola. Como es sabido, las series oficiales de producción arrancan de la década de 1880 , están limitadas a los principales cultivos -inicialmente, sólo cereales-, y por distintas razones son vistas con desconfianza por los historiadores. Por lo que respecta al periodo anterior a su arranque, la situación es incomparablemente peor, al poseer sólo el controvertido conjunto de cifras del Censo de Frutos y Manufacturas, el aún más controvertido que data de 1857 , y poco más. En cuanto a las productividades del trabajo y de la tierra, las deficiencias de nuestras cifras de producción, tierra cultivada y (en menor medida) población activa comprometen seriamente cualquier intento. Las fuentes locales proporcionan información directa $-\mathrm{y}$ relativamente abundante - sobre los rendimientos de la tierra, pero su fiabilidad y representatividad son debatibles. En este estado de cosas, la tentación de acudir a estimaciones indirectas es fuerte. Prados (1988 y 1995) y Simpson (1989) han tratado de deducir el producto agrícola a partir de cifras sobre población o transporte. Ahora bien, sus intentos dependen en gran medida de sus supuestos relativos al consumo per cápita, los cuales, a su vez, remiten al cálculo del PIB. Más recientemente, en la reciente tesis de Miguel Ángel Gutiérrez Bringas se ha optado por una estrategia diferente ${ }^{5}$. La idea básica es: si no podemos calcular las productividades medias del trabajo y de la tierra, calculemos sus productividades marginales. Como es sabido, en mercados competitivos el precio de un factor equivale a su productividad marginal en valor. Esto es, dado el factor " $\mathrm{f}$ ", usado en la producción del bien " $\mathrm{g}$ ", $\mathrm{P}_{\mathrm{f}}=\mathrm{PMa}_{\mathrm{f}} \cdot \mathrm{P}_{\mathrm{g}}$. De aquí se sigue que el cociente resultante de dividir el precio del factor por el precio del bien producido nos proporciona una medida de la productividad marginal física de ese factor. A partir de este simple principio, Gutiérrez Bringas ha aprovechado la información —comparativamente rica- que existe sobre precios de productos y factores, ha dividido dos índices de salarios agrícolas y de precios de la tierra entre un índice de precios de los productos, y como resultado ha estimado dos series de productividades del trabajo y de la tierra (véanse figuras 1 y 2 ). Por ahora, las dos series son discontinuas, pero permiten hacerse una idea de la tendencia temporal de las variables correspondientes, así como determinar qué cifras de productividad media son fiables y cuáles no lo son.

De hecho, Coll y Gutiérrez Bringas (1995) han empleado la información sobre precios de productos y factores para estimar la evolución de la pro-

${ }^{5}$ Véase Gutiérrez Bringas ( 1998 y 2000). 


\section{FIGURA 1}

Productividad de la tierra cultivada, 1818-1935

(Numeros indices, 1930/35 = 100)

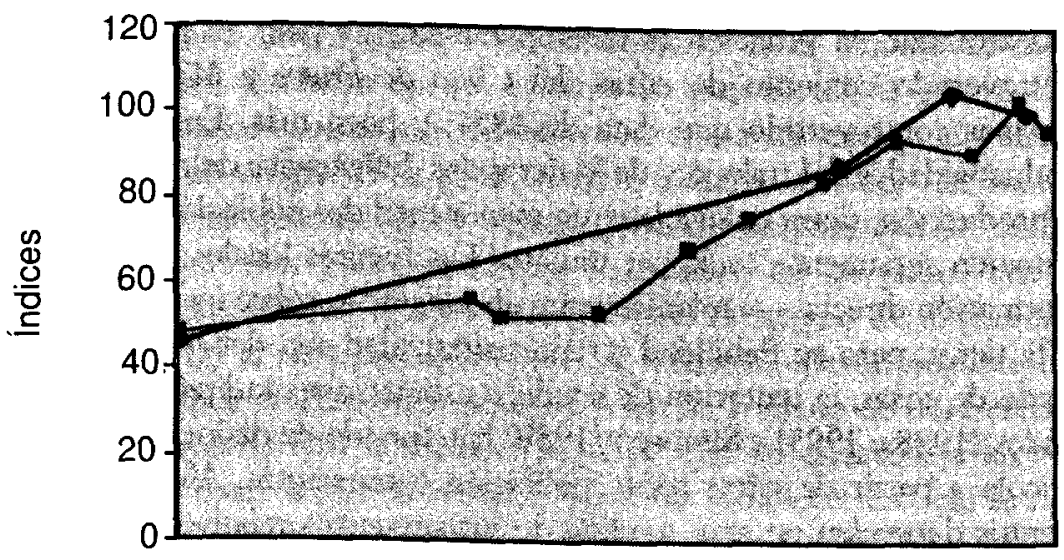

Años

FuENTE: Gutiérrez Bringas (1998), p. 100.

ductividad total de los factores, así como la de la producción ${ }^{6}$. Se atribuye a Jorgenson (1966) el descubrimiento de que, cuando la función de producción es del tipo Cobb-Douglas, la productividad total de los factores se puede estimar, bien como un índice Divisia de los precios de los factores divididos entre los precios de los productos, o como un índice Divisia de las cantidades de productos divididas entre las cantidades de factores. Historiadores económicos como North (1968), McCloskey (1973 y 1981), Crafts (1985), Harley (1988), Hoffman (1991) y otros han hecho uso de esta propiedad. Coll y Gutiérrez Bringas se tomaron el trabajo de comprobar que, efectivamente, la forma Cobb-Douglas describe bien la función de producción de la agricultura española del siglo XIX - la cual, según

\footnotetext{
"Véase Coll y Gutiérrez Bringas (1998) para una versión breve de su trabajo.
} 
FIGURA 2

Productividad del trabajo, 1751-1935

(Números índices, $1930 / 35=100$ )

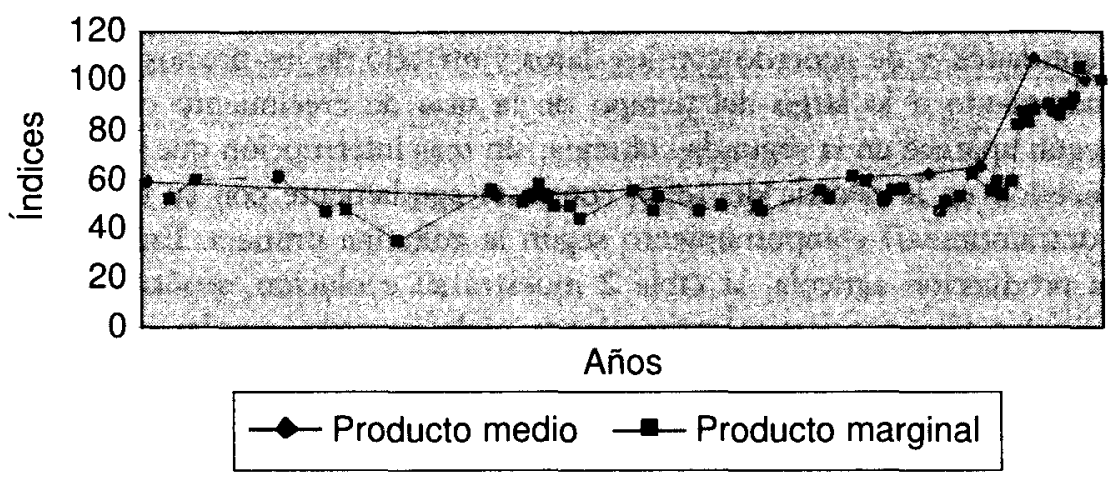

FuENTE: Gutiérrez Bringas (1998), p. 191.

sus cálculos, se ajusta de hecho a los datos mejor que cualquier otra forma funcional- y, a partir de aquí, han podido estimar no sólo la productividad total de los factores sino la producción agrícola como tal. Siempre de acuerdo con Jorgenson, un índice de precios de los factores dividido entre otro índice de precios de los productos es lo mismo que un índice de cantidades de los productos dividido entre otro de cantidades de los factores, por ser ambos cocientes iguales a la productividad global. Ahora bien, si tenemos datos sobre precios de productos y factores y sobre las cantidades de factores, entonces resulta posible calcular un índice para las cantidades de productos. En la práctica, el problema se complica un poco por la ausencia de datos fiables sobre la cantidad de tierra cultivada en la España del siglo XIX. Sin embargo, sabemos que los funcionarios españoles calculaban la producción a partir de las cifras de superficie cultivada, multiplicándolas por los rendimientos medios. Tenían conocimiento de primera mano, aunque impreciso, sobre estos últimos, el cual, de acuerdo con nuestras estimaciones indirectas sobre productividad de la tierra, resultaba ser bastante bueno. De esta manera, las cifras oficiales sobre producción agrícola y sobre tierra cultivada tienen que presentar la misma tasa de ocultación, la cual se convierte así en la única incógnita de nuestra ecuación. 
Despejándola, Coll y Gutiérrez Bringas han obtenido unas estimaciones corregidas de la producción agrícola en aquellos años para los cuales disponemos de cifras oficiales.

La tabla 1 muestra las tasas de crecimiento de la productividad total de los factores, según se deducen de las cifras oficiales y fórmula de las cantidades, y de acuerdo con los datos y método de los precios. El suave incremento a lo largo del tiempo de la tasa de crecimiento de la TFP según aparece en la segunda columna, sin más interrupción que una breve recesión en la década de 1890, contrasta agudamente con su errático (y contraintuitivo) comportamiento según la columna primera. En cuanto a la producción agrícola, la tabla 2 muestra su evolución, según las cifras oficiales, según nuestras estimaciones y de acuerdo con las de Prados (1995). De nuevo, nuestro índice difiere notablemente del oficial, al tiempo que se asemeja mucho al de Prados. Dadas las reservas expresadas más arriba hacia los supuestos de este autor, parece justo declarar ahora que los cálculos de Coll y Gutiérrez Bringas parecen reafirmar la validez de sus conclusiones.

\section{TABLA 1}

Tasas de crecimiento anual de la productividad total de los factores en la agricultura española, 1799-1931 (porcentaje)

\begin{tabular}{|c|c|c|}
\hline Periodos & $\begin{array}{c}\text { Calculada a partir } \\
\text { de cantidades }\end{array}$ & $\begin{array}{c}\text { Calculada a partir } \\
\text { de precios }\end{array}$ \\
\hline $1799-1931 \ldots \ldots \ldots \ldots \ldots \ldots \ldots \ldots \ldots$ & 0,61 & 0,58 \\
\hline 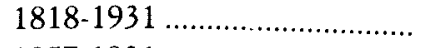 & 1,16 & 0,76 \\
\hline 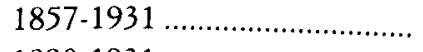 & 1,52 & 0,92 \\
\hline 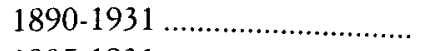 & 0,77 & 0,74 \\
\hline 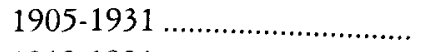 & 1,04 & 1,13 \\
\hline 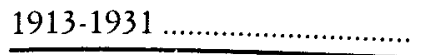 & 1,31 & 1,29 \\
\hline
\end{tabular}

FUENTE: Gutiérrez Bringas (1998), p. 246.

Más que seleccionar una única y definitiva respuesta a un determinado problema histórico, lo que suele hacer la cliometría es proponer explicaciones plausibles, dotadas de consistencia interna - esto es, lógica-, y consistentes también con la información disponible. Como esto no es un panorama, sino solamente una selección de ejemplos, voy a permitirme 


\section{TABLA 2}

Indices de la producción agrícola en España, 1799-1931

$(1931=100)$

\begin{tabular}{|c|c|c|c|}
\hline$A n ̃ o s$ & $\begin{array}{c}\text { Indice basado } \\
\text { en cifras oficiales }\end{array}$ & $\begin{array}{l}\text { Nuevo } \\
\text { indice }\end{array}$ & $\begin{array}{c}\text { Indice de Prados } \\
\text { (1995) }\end{array}$ \\
\hline 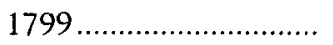 & 25,5 & 28,0 & n.d. \\
\hline 1818 . & 14,0 & 27,2 & n.d. \\
\hline 1857. & 28,4 & 45,7 a 47,5 & 47,3 \\
\hline $1890 \ldots \ldots \ldots \ldots \ldots \ldots \ldots \ldots \ldots \ldots \ldots \ldots \ldots \ldots \ldots \ldots$ & 59,3 & 68,5 & 68,3 \\
\hline $1905 \ldots \ldots \ldots \ldots \ldots \ldots \ldots \ldots$ & 71,1 & 72,5 & 77,2 \\
\hline 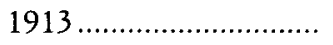 & 77,3 & 83,7 & 81,6 \\
\hline $1931 \ldots \ldots \ldots \ldots \ldots \ldots \ldots$ & 100,0 & 100,0 & 100,0 \\
\hline
\end{tabular}

Fuente: Gutiérrez Bringas (1998), p. 292, y Prados (1995), pp. 90-91.

elegir uno que parece encontrarse en las antípodas de las preocupaciones iniciales de la NHE: me refiero al surgimiento de los primeros imperios de la Antigüedad. ¿Por qué algunas civilizaciones antiguas dieron lugar al nacimiento de grandes imperios mientras que otras se contentaban con la creación de ciudades-estado? Algunos cliómetras han tratado de responder a esta vieja pregunta, fundando sus interpretaciones en consideraciones de coste y beneficio. Dicho brevemente, se creaban imperios cuando y donde traía cuenta crearlos. Y para llegar a esta conclusión, hay que poner bajo la lupa los costes y beneficios de los imperios.

Historiadores y otros científicos sociales han formulado diversas teorías sobre la creación de imperios, las cuales, al menos en parte, descansan en consideraciones de beneficio. Entre éstas está la formulada por Carneiro (1970), según el cual es más probable que surjan imperios en áreas fértiles rodeadas por desiertos u otras barreras infranqueables. Como estos obstáculos impiden a los conquistados votar con los pies y abandonar su tierra natal, la conquista de áreas así delimitadas asegura tributos y/o mano de obra forzada. Ello aumenta la probabilidad de que la conquista sea una empresa rentable, al contrario de lo que sucede cuando hay un continuo de tierra cultivable a lo largo del cual los derrotados pueden huir hacia lugares más seguros. Esta teoría, sin embargo, conlleva el riesgo de inconsistencia. En efecto, sólo si la totalidad del área «delimitada» ha sido pobla$\mathrm{da}$, podemos decir con toda propiedad que está «delimitada». Ahora bien, 
para cuando esa tierra esté totalmente poblada, es posible que la densidad de población sea alta. Como la esclavitud y la servidumbre sólo traen cuenta en condiciones de baja densidad de población ${ }^{7}$, la existencia comprobada de esclavos en los primeros imperios podría interpretarse como prueba en contra de la teoría. A mayor abundamiento, el supuesto de poblamiento completo del territorio parece inconsistente con la experiencia de Egipto. Así pues, parece que se necesita un análisis económico más fino. El cliómetra Robert C. Allen (1997) ha desarrollado esta teoría, ampliándola al caso de baja densidad de población. Según él, el poblamiento de toda la tierra no es requisito necesario para que una parte de sus habitantes emprenda la conquista del todo. Antes bien, la conquista del todo sí es un requisito para el éxito a la hora de impedir la huida de los conquistados hacia tierra no ocupada. En definitiva, la hipótesis original puede ampliarse para tomar en cuenta un rango mayor de casos, y el empleo de razonamiento económico explícito y completo parece ser conveniente incluso cuando se trata de refinar hipótesis brillantes y útiles como la de Carneiro.

Sin embargo, algunos imperios crecieron por encima de los límites de esas áreas «delimitadas», siendo el caso de Roma el más evidente. Y es que la consideración sólo de los beneficios, sin atención a los costes, resulta incompleta. El economista Leonard Dudley (1990 y 1991) ha hecho una interesante adaptación del modelo de equilibrio de la empresa en el largo plazo a la actividad guerrera del Estado, con vistas a explicar el surgimiento de esos inmensos imperios. De acuerdo con el modelo, en el largo plazo la empresa alcanzará aquel tamaño que minimice el coste medio: si su tecnología presenta rendimientos crecientes a escala, la empresa crecerá, y si aparecen rendimientos decrecientes a escala, dejará de crecer. Fijándonos ahora en la tecnología militar, existen rendimientos crecientes a escala siempre que varios combatientes puedan luchar simultáneamente contra uno solo. El combate con armas de fuego proporciona un buen ejemplo, aunque el mismo fenómeno aparece también cuando se emplean otras técnicas. En todos estos casos, los rendimientos crecientes aparecen porque, caeteris paribus, las bajas sufridas por cada bando dependen del número de combatientes enemigos. Así, el número absoluto de bajas en el ejército más grande resulta ridículamente bajo comparado con las del ejército más pequeño. Por el contrario, otras técnicas guerreras como el combate a caballo no permiten que varios combatientes luchen a la vez contra uno

${ }^{7}$ En caso contrario, la competencia entre los sin tierra deprime los salarios y eleva las rentas de la tierra, de manera que los arrendamientos o la explotación directa con mano de obra asalariada aseguran elevados ingresos a los terratenientes. 
solo. De esta manera, lo que tenemos es un combate repetido de uno contra uno, y el número final de bajas estará equilibrado, sin importar la diferencia entre los tamaños de los dos ejércitos. En otras palabras, algunas técnicas de guerra reducen los costes de un determinado objetivo militar para los ejércitos grandes, mientras que otras los hacen iguales para ejércitos grandes y pequeños: las primeras favorecerían el surgimiento de imperios, mientras que las últimas lo desincentivan. Dudley relaciona, por ejemplo, el surgimiento del imperio romano con la adopción de la tecnología militar romana. Las legiones, equipadas con armas arrojadizas, lo bastante maniobrables como para rodear a las unidades enemigas, y poseedoras de una avanzada tecnología de asedio, proporcionaban rendimientos crecientes a escala en la guerra. A la inversa, una vez que el estribo y otros avances mejoraron la eficiencia de la caballería, los rendimientos constantes a escala se convirtieron en la norma, toda vez que un caballero a la carga sólo tiene que preocuparse del jinete enemigo que está directamente enfrente de él. Así, la caída del imperio romano y su sustitución por unidades políticas cada vez más pequeñas aparecen como los resultados naturales de esta técnica de combate de uno contra uno. Otra vez, la historia no es completamente nueva, puesto que la importancia del estribo en relación con las invasiones bárbaras y con el ascenso del feudalismo había sido puesta de manifiesto por Lynn White (1962) y por otros a continuación. Sin embargo, la explicación propuesta por Dudley resulta mucho más completa. De hecho, la explicación de este autor contempla también el lado de los beneficios. Siempre según Dudley, los ingresos netos que llegan a la metrópoli serían decrecientes en el margen, debido a que los costes de agencia aumentan con el tamaño del Estado. Así, resulta posible establecer el tamaño óptimo del Estado bajo el supuesto de que esclavos, botín y tributos sean los únicos bienes públicos que éste ofrece a sus ciudadanos. La figura 3 muestra ese equilibrio, mientras que la figura 4 indica los resultados de la desaparición de los rendimientos crecientes a escala en la guerra. Estos resultados se resumen en un menor tamaño de la unidad política y en impuestos más elevados, predicciones ambas que parecen consistentes con la experiencia europea posterior a la caída del imperio romano. De hecho, se podría argumentar que los costes de agencia no son del todo exógenos, sino que harían pivotar hacia la izquierda la curva de coste marginal al debilitarse la integración política. Así, se podría imaginar un modelo dinámico de la conquista bárbara, cuyo resultado sería un tamaño cada vez más pequeño de la unidad política efectiva. 


\section{FIGURA 3}

Tamaño de la unidad politica y presión fiscal cuando la tecnología militar favorece a los ejércitos grandes

\section{Presión fiscal}

\section{esperada}

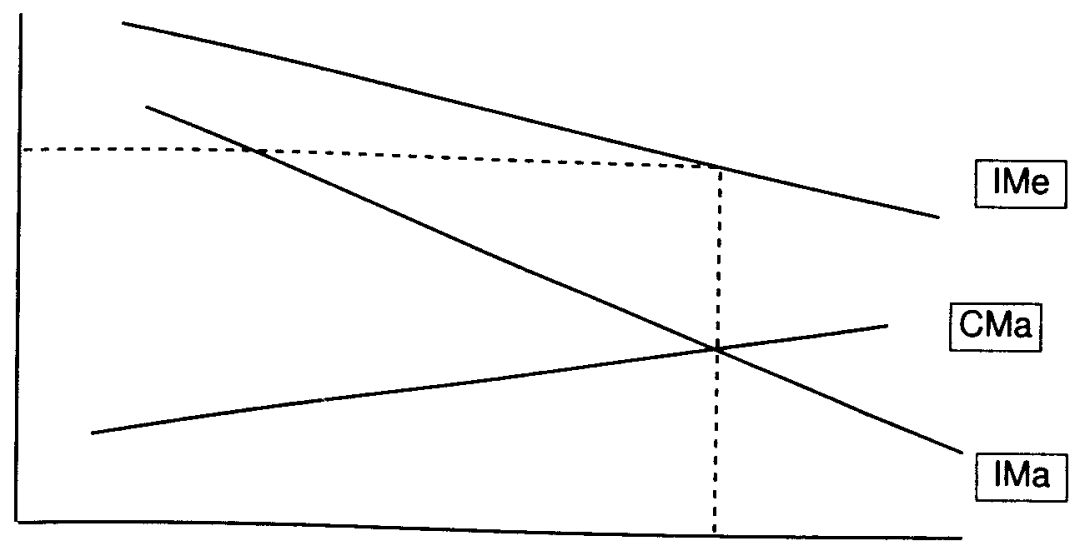

\section{Tamaño esperado de la unidad política}

Fuente: Dudley (1990), p. 227.

Mi propósito oculto al elegir este ejemplo, propósito que ahora puedo revelar, era mostrar cómo «la reunificación de la historia económica con la teoría económica» - tal era el título de un artículo de Robert Fogel publicado en 1965 - no ha redundado en perjuicio de la Historia. Antes bien, puede ayudar a la Historia a formular hipótesis con vistas a la explicación de los grandes problemas a los que se enfrenta.

\section{L.A HISTORIA ECONÓMICA, ENTRE LA AUTOSATISFACCIÓN Y EL DESALIENTO}

A pesar de logros como los arriba mencionados, los historiadores económicos - y señaladamente los cliómetras - se debaten hoy entre la satis- 


\section{FIGURA 4}

Tamaño de la unidad politica y presión fiscal

cuando la tecnologia militar no favorece a los ejércitos grandes

\section{Presión fiscal}

\section{esperada}

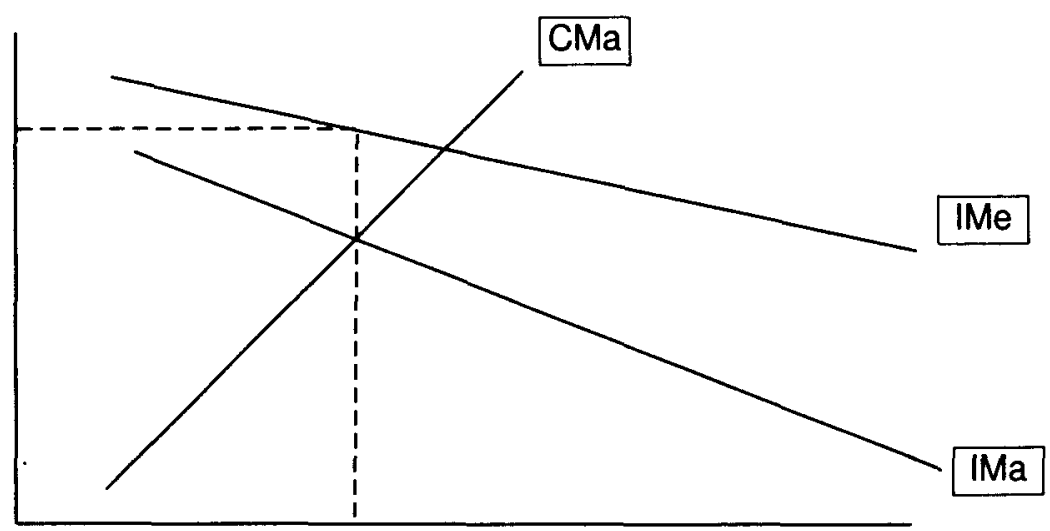

Tamaño esperado de la unidad política

FuENTE: Dudley (1990), p. 237.

facción y el desencanto, sentimiento que se constata en un número no desdeñable de trabajos. Estaba presente, por ejemplo, en las contribuciones presentadas a un encuentro de la Asociación Económica Americana que tuvo lugar en 1984 en Dallas, dentro de una sesión titulada Historia Económica: una condición necesaria aunque no suficiente para un economista ${ }^{8}$. A pesar de que los ponentes invitados - los profesores Arrow y Solow en representación del punto de vista de los economistas, más un número de historiadores económicos- no ocultaban su simpatía hacia la historia económica y se mostraban sinceramente preocupados por la ignorancia cada vez mayor de la Historia corriente entre los economistas y otros cien-

${ }^{8}$ Las ponencias y los comentarios a las mismas fueron más tarde publicados en formato de libro. Véase Parker (ed.) (1986). 
tíficos sociales, resultaba igualmente claro que las verdaderas demandas planteadas a la historia económica por los teóricos rara vez son satisfechas por aquélla. Otra obra colectiva sobre El futuro de la Historia Económica, editada en 1987 por Alexander Field, desprendía el mismo tufillo lúgubre, especialmente en el capítulo introductorio a cargo del editor. La preocupación parece compartida por otros autores, como McCloskey (1986) o E. L. Jones (1990), y no perdona a los (supuestamente entusiastas) cliómetras europeos: otros artículos de Crafts (1987) y Dumke (1992) también destilan gotas del mismo pesimismo.

Detrás de tal pesimismo uno puede adivinar algunas razones comunes al conjunto del mundo académico. Por ejemplo, el fin del boom universitario en muchos paises ha impuesto un alto a las perspectivas de carreras rápidas para los nuevos ( $\mathrm{y}$ no tan nuevos) entrantes a la profesión académica, y agrava la pugna por puestos y cursos entre las disciplinas, con el resultado de que la historia económica se encuentra bajo presión en las facultades de económicas. Sin embargo, ni es ésta toda la historia, ni todas las razones para esa presión tienen un origen tan bastardo: en parte, el desaliento de los historiadores económicos nace del sentimiento de que su trabajo no es apreciado ni por los historiadores generales ni por los economistas. A los primeros les desanima el empleo que hacen los historiadores económicos de la jerga económica y de las técnicas cuantitativas, incrementado como consecuencia de la revolución cliométrica. En el mejor de los casos, los historiadores generales se contentan con aceptar pasivamente los manuales que escriben los historiadores económicos, pero no muestran interés por las monografías y las revistas del área ${ }^{9}$. En cuanto a los economistas, los frutos de la revolución cliométrica han tenido un efecto inesperado. En la medida en que los historiadores económicos han erigido como sus supremos valores la aplicación de la teoría económica y el empleo de las técnicas econométricas, el resultado es que, simplemente, tienen muy poco que enseñar a los economistas. Como Field (1987) apuntaba con amargura, después de haber ponderado tanto la utilidad de la teoría económica y de la econometría, los historiadores económicos no deberían extrañarse

${ }^{9}$ En otro ejercicio de adivinación sobre el futuro de la historia económica, Tilly, Tilly y Tilly (1991, p. 647), abogaban por «deseconomizar la historia económica y reeconomizar la bistoria social» (la cursiva es suya). Aunque no puedo estar más de acuerdo con su recomendación, y aunque trabajos como los de Allen (1997) o Dudley (1990 y 1991) hacen exactamente aquello que los Tilly aconsejaban, el beneficio de casi una década de experiencia - el plazo que estos autores marcaban a su previsión- permite afirmar que esos ejemplos siguen siendo escasos, tienden a pasar desapercibidos para los historiadores no económicos, $y$, en definitiva, que las esperanzas de los Tilly no se han visto cumplidas. 
de que los departamentos a los que pertenecen prefieran fichar a un teórico o a un económetra antes que a un historiador económico.

En términos de cálculo marginal, seguirá habiendo algunos puestos y cursos de historia económica en los departamentos de economía, en la medida en que la contribución marginal del primer historiador económico, que aplique la teoría y las matemáticas a historias viejas, quizá sea valorada por encima de la que pueda hacer el enésimo especialista en la aplicación de parecidas herramientas a casos más recientes. Es más, para determinados problemas que preocupan a los economistas puede no haber evidencia contemporánea suficiente o debidamente documentada, de manera que los mejores ejemplos sigan procediendo del pasado. Así, las experiencias centroeuropeas de los años veinte siguen proporcionando los ejemplos clásicos de hiperinflación y subsiguiente estabilización, y los años treinta siguen ofreciendo el ejemplo de libro para una depresión económica. Los temas como éstos hacen que los economistas presten cierta atención a la historia económica, pero hay que reconocer que su lista, aunque ampliada en los últimos tiempos ${ }^{10}$, no es lo bastante larga como para hacerles mantener esa atención. Por si eso fuera poco, demasiados economistas prefieren hacer su propia interpretación de lo que consideran ser «los hechos» pasados, ignorando las más recientes contribuciones de los historiadores económicos, con el resultado de que a bastantes de esos economistas se les podría aplicar aquello que Keynes decía de quienes presumían de tener ideas económicas originales: esto es, que en el fondo resultan ser esclavos de algún historiador económico difunto; sin embargo, como no lo saben, hay poca esperanza de que rectifiquen.

A pesar de lo anterior, sería demasiado simple echar a los economistas toda la culpa de su desatención por la historia económica. Por lo que respecta a los pecados de los historiadores, permítaseme ilustrar el punto

${ }^{10}$ Recientemente, Jeffrey Williamson ha mostrado cómo la experiencia anterior a la Primera Guerra Mundial puede proporcionar enseñanzas útiles en relación con la actual preocupación por las consecuencias de la globalización y la inmigración a los países desarro. llados. Algo similar sucede con el proceso de integración monetaria europea, con el crecimiento de las ciudades del Tercer Mundo o con el debate acerca de las causas del reciente incremento de la desigualdad en la distribución del ingreso y la riqueza constatado en los Estados Unidos: sobre este último punto, los trabajos de Williamson (1997 y 1998) presentan una relevancia innegable. Asimismo, los historiadores ecorómicos deberian quizá decidirse $\mathrm{y}$ aportar sus contribuciones al debate sobre las causas del aumento del desempleo en Europa, como ha hecho Reher (2000) a propósito del caso español, o sobre las consecuencias para el mismo del progreso técnico. Por lo que a España respecta, una relación de temas en los que la Historia importa - y un buen ejemplo de economista interesado por la mismapueden encontrarse en Fuentes Quintana (ed.) (2000). 
con la parábola que empleaba Solow (1986), hablando del escaso interés que despierta la mayor parte de la historia económica desde el punto de vista del teórico:

La situación me recuerda a una historia que oí contar una vez a una antropóloga que había pasado unos meses recopilando los mitos y leyendas de un grupo de apaches en Nuevo Méjico. Una noche, justo antes de terminar su trabajo de campo y volverse a casa, los indios le dijeron: "Nos hemos pasado todos estos meses contándote nuestras leyendas; ¿por qué no nos cuentas una de las vuestras?" La antropóloga pensó con rapidez, y salió airosamente del trance contándoles a los indios una versión de la historia de Beowulf. Años después, ojeando un ejemplar de una revista de antropología, se encontró en el índice con un artículo titulado "Sobre la existencia entre los apaches tal y tal de una leyenda parecida a la de Beowulf".

No hace falta añadir que el único interés que podía encerrar el artículo en cuestión para la protagonista era el humorístico.

El hecho es que la teoría económica actual no es, en su mayor parte, «una investigación sobre la naturaleza y causas de la riqueza de las naciones». Más bien es un conjunto, aunque articulado con lógica, de modelos enfocados principalmente al corto plazo y aislados del mundo exterior por una lista de restricciones y supuestos simplificadores. El análisis de equilibrio estático es la herramienta favorita de los economistas; sin embargo, muchos de los problemas económicos más interesantes son de naturaleza dinámica. Los economistas teóricos suponen constantes muchas condiciones a lo largo del período analizado; ahora bien, este supuesto es claramente inadecuado en el largo plazo. La mayor parte de los teóricos no se pregunta cómo han llegado a darse esas condiciones, por lo cual no puede predecir cuándo pueden cambiar y en qué dirección. Asimismo, en el corto plazo es posible que la causalidad entre dos variables vaya en un solo sentido; sin embargo, es dudoso que podamos considerarlo así en un plazo más largo. Luego, cuando los teóricos hablan de eficiencia, siempre se refieren a eficiencia estática; no obstante, como ya indicó Schumpeter (1942), cabe en principio la posibilidad de que una institución u organización económica, o un modelo de mercado, sea eficiente desde un punto de vista estático, pero ineficiente desde un punto de vista dinámico, o a la inversa. Como último ejemplo de las limitaciones de la teoría y de su aplicación a la Historia, el análisis de equilibrio general identifica numerosas restricciones -relativas a aspectos distributivos y de otro tipo- que deben cumplirse para que podamos considerar al crecimiento del PIB como algo inequívocamente deseable. Se supone que esas condiciones se cumplen en el 
corto plazo; sin embargo, es improbable que lo hagan en el largo plazo, y no hace falta decir que ello pone en cuestión el significado económico de esas largas series temporales del PIB y de los enormes esfuerzos que dedicamos los historiadores económicos a su construcción.

$\mathrm{Al}$ enumerar esta lista de limitaciones no pretendo negar la utilidad de la teoría económica, ya sea sola o aplicada al análisis del pasado: creo que mi lealtad a la causa habrá quedado suficientemente probada en la sección anterior. Mi intención es, más bien, destacar el carácter inacabado de la teoría económica actual, y la mayor incidencia que sus lagunas tienen para la historia económica. Los historiadores económicos son conscientes de esta situación, pero también de su incapacidad para remediarla, y ésta es una razón importante de la desilusión que provocamos, tanto en nosotros mismos como entre los economistas. Como indicaba Field (1987), fue sintomático que los historiadores económicos invitados al encuentro de la Asociación Económica Americana de 1984 que mencionamos más atrás adoptasen una aproximación indirecta al tema de la contribución de la historia económica a la formación de los economistas, y optasen por contar parábolas en lugar de precisar cómo exactamente puede la historia económica contribuir a la construcción de la ciencia económica. Sin embargo, tampoco Field hacía otra cosa más que suscitar la cuestión, sin apuntar, él tampoco, a soluciones.

Así pues, los historiadores económicos se sienten a menudo como mercaderes sin flete de retorno. Exportan productos del país de los Econ a tierras de la Historia, pero ni producen ni venden gran cosa a ese primer territorio. En alguna medida, éste puede ser un efecto del diferente status científico de las disciplinas académicas: seguramente, las matemáticas también exportan más de lo que importan, la física mantiene una balanza comercial bilateral negativa con las matemáticas y positiva con otras ciencias, y así sucesivamente. No obstante, una vez que las necesidades del potencial consumidor han sido identificadas, resulta frustrante no satisfacerlas.

\section{SEÑALES DE AMISTAD DESDE LA TIERRA DE LA ECONOMÍA}

Alguien ha dicho que, en la actualidad, los Econ componen una federación laxa, más que una entidad compacta ${ }^{11}$. En la periferia de su territorio

1 En concreto, Jones (1990), pp. 158-159. 
habitan tribus más pequeñas, algunas de las cuales simultanean una preocupación especial por temas del largo plazo con una entrañable inclinación hacia la Historia. Mi objetivo en esta sección y en la siguiente es argumentar que las posibilidades de que la historia económica haga una verdadera contribución a la construcción del edificio de la economía pasan por su colaboración con esas subdisciplinas ${ }^{12}$. Que esa contribución vaya a ser grande o pequeña es algo que nadie puede adivinar; sin embargo, me parece que no hay alternativa real.

Uno de los miembros más exóticos de la gran familia de la economía es la economía del desarrollo. Sus practicantes ven el análisis de equilibrio de manera muy parecida a como lo hacen los historiadores económicos, esto es, con sentimientos que van desde el «sí, pero» hasta la hostilidad abierta. En el fondo, su grupo es tan heterogéneo como el que compone el conjunto de los economistas, y es posible que los economistas ortodoxos tengan razón cuando estigmatizan a parte de la economía del desarrollo como algo inútil. Sea como fuere, los miembros de este grupo comparten un conjunto común --aunque limitado- de rasgos. Así, a menudo coinciden en desdeñar la causalidad unidireccional de los modelos económicos simples, prefiriendo hablar de causalidad circular, de círculos viciosos $\longrightarrow$ virtuosos- y de procesos acumulativos, y, en general, les gustaría complementar el mecanismo actual del análisis económico para convertirlo en una máquina multiusos. Los economistas ortodoxos suelen arrugar la nariz ante sus diseños, que les parecen algo así como un coche atado con cuerdas, y a veces cunde el desánimo entre los economistas del desarrollo; pero cada cierto tiempo vuelven a la arena con un modelo nuevo.

Muchos especialistas en economía del desarrollo ven a ésta y a la historia económica básicamente como la misma cosa, idea que algunos de ellos han expresado en términos convincentes: a título de ejemplo, véase Feeny (1987). Desde luego, hay varios (y famosos) pioneros que han hecho su hogar en la frontera entre los dos territorios. David Feeny, Jeffrey Williamson y otros proporcionan buenos ejemplos, aseguran la rápida transmisión de las posibles novedades en los dos sentidos, y ellos mismos han llevado a cabo innovaciones. Su ejemplo invita a pensar que la fertilización mutua

${ }_{12}$ Por supuesto, no quiero decir que una colaboración similar con la corriente principal de la economía vaya a ser infructuosa. Al contrario, los historiadores económicos tienen aún mucho que aprender de la teoría stanclard, así como de sus recientes desarrollos. Pongo por ejemplo las posibilidades que brindan a la historia económica los nuevos modelos de la economía industrial, la economía de la información o la teoría de juegos. Lo que quiero decir es que la colaboración con estos campos seguirá siendo asimétrica, básicamente en beneficio de la historia económica. 
de estas dos variedades de la misma especie es capaz de producir buenos híbridos.

La economía del crecimiento comparte con la economía del desarrollo el interés por el largo plazo. Sin embargo, las dos subdisciplinas son opuestas en más de un sentido. Los economistas del crecimiento están firmemente anclados en la teoría económica ortodoxa, sólo aceptan relajar de una en una las restricciones habituales en ésta, y, en la práctica, a lo largo de los últimos cuarenta años sólo se han mostrado dispuestos a admitir que la tecnología avanza, sin querer saber nada sobre cambio institucional y similares: a lo más que llegan en estos terrenos es a afirmar que la inestabilidad política y social le sienta mal al crecimiento económico ${ }^{13}$. Todo esto es consecuencia de su apego por la formalización, el cual también explica otra característica suya: los economistas del crecimiento odian la charla sin números, y cuando éstos les faltan — cosa que sucede con frecuencia, dado el carácter inusitado de sus demandas- sólo aceptan reemplazarlos por letras griegas. A mayor abundamiento, los economistas del crecimiento se adhieren con fervor a la proposición de Friedman según la cual una hipótesis sólo es importante si explica mucho a partir de poco, de modo que las explicaciones monocausales son preferibles a las multicausales. Así, sus nuevos modelos de crecimiento endógeno reducen siempre el cambio técnico a una sola causa o indicador, sea éste la acumulación de capital humano, el aprendizaje por la práctica, las externalidades de la inversión pública, las economías de escala o la inversión en I + D.

En este respecto, sin embargo, a los historiadores económicos les sale el historiador, más que el economista, y prefieren una explicación multicausal del crecimiento. A decir verdad, el problema con los modelos de crecimiento endógeno parece estar precisamente en que todos ellos se muestran capaces de explicar el crecimiento, a pesar de fijarse en variables explicativas diferentes. Dejando a un lado estas diferencias, ha habido algún comercio entre los economistas del crecimiento y los historiadores económicos, así como algunos notorios intermediarios entre ambos, como Moshes Abramovitz o Bradford DeLong. Los economistas del crecimiento dependen de sus importaciones de datos, y de vez en cuando los historiadores económicos toman prestados conceptos y técnicas de la economía del crecimiento: ya hemos visto antes el caso de la productividad total de los factores. Más recientemente, historiadores económicos se han lanzado al debate sobre la convergencia, aunque no siempre con plena con-

\footnotetext{
${ }^{13}$ Como hace Barro (1991), p. 437.
} 
ciencia de su significado y orígenes en economía del crecimiento. También los dos grupos hacen uso extensivo del concepto de capital humano, que han tomado prestado de un tercero, $y$, por último, también en los noventa, algún economista del crecimiento, como Michael Kremer (1993), se ha aventurado en el análisis del muy largo plazo, mientras que a algunos historiadores económicos, como Ann Carlos y Frank Lewis (1995), se les ha visto enredar con el control óptimo, que es uno de los juguetes favoritos de la moderna economía del crecimiento.

En la lista de escuelas económicas que no pertenecen a la corriente principal, le toca el turno a la economía neoinstitucional. Para empezar, la nueva economía institucional prescinde de la mayor parte de los supuestos restrictivos habituales de la teoría económica standard, para quedarse revestida únicamente con la hoja de parra de la racionalidad - mejor si lleva el adjetivo «limitada»-y el comportamiento optimizador. Los derechos de propiedad, las empresas, los mercados, el dinero, el Estado y todo lo demás se convierten en creaciones endógenas de unos humanos racionales y egoístas a lo largo de la historia. La nueva economía institucional está deseosa de evidencia histórica y antropológica que le permita observar las formas más simples de vida institucional y ampliar su campo de observación para incluir en él a las sociedades no democráticas del pasado, y, al mismo tiempo, los historiadores económicos inteligentes se muestran, con pocas excepciones ${ }^{14}$, encantados de encontrar esa teoría «histórica», capaz de endogeneizar a todas las variables y de convertir a los resultados pasados en determinates de los resultados futuros. No es de extrañar, pues, que ambas disciplinas mantengan un activo intercambio, que hasta la fecha ha dado lugar a algunas creaciones excepcionales: las obras de North o la de Eggertsson (1990) proporcionan ejemplos emblemáticos.

En cuanto a la teoría de la empresa, se puede ver como un caso dentro de la economía institucional, al menos en su versión costes de transacción. Los economistas de la empresa son seguramente los miembros más díscolos de la confederación Econ, aunque de nuevo pueden hacerse distingos entre ellos. Algunas de sus tribus se han ganado a pulso la pésima reputación de que disfrutan, mientras que otras se muestran al mismo tiempo respetuosas con los tótems de los Econ y amistosas con sus vecinos a este lado del río, esto es, con los historiadores de la empresa; parecen estimar los trabajos de historiadores de la empresa como Alfred Chandler, y, junto a historiadores económicos y economistas neoinstitucionalistas, se consideran descendientes del patriarca Ronald Coase.

${ }^{14}$ Como excepción, véase Field (1980). 
En tiempos recientes, la historia económica también empieza a prestar atención a los guiños prometedores que le llegan desde la economía del cambio tecnológico. Siempre deseosa de hurgar en la caja negra de los avances técnicos - cosa que la economía del crecimiento se niega a hacer-, esta corriente está dando señales de notable vitalidad en las últimas décadas. En paralelo con esa renovada actividad, los analistas económicos del cambio técnico han desarrollado un gusto especial por determinados productos de la historia económica. Así, muchos de ellos se definen como neoschumpeterianos - para vergüenza de los historiadores económicos, que hemos olvidado a este defensor de la importancia de la Historia con vistas a la construcción de la Economía-, y aprecian la obra de historiadores económicos de la tecnología como Nathan Rosenberg.

Dados la larga tradición de análisis económico del cambio técnico y el papel vital que los historiadores económicos atribuyen a éste, llama la atención la falta de un contacto más intenso entre unos y otros en el pasado, tanto más cuando los pioneros del análisis económico del cambio tecnológico, como fue Schmookler, frecuentaron los mismos sectores y períodos de tiempo que analizaban los historiadores económicos coetáneos. Sin embargo, hoy en día encontramos de nuevo a unos pocos académicos que mantienen un pie en cada orilla, como es el caso notable de Paul David.

A todo esto, no hemos dicho qué es lo que hacen los analistas económicos del cambio técnico. La heterogeneidad del grupo impide dar una respuesta breve a esta pregunta; no obstante, se pueden destacar algunos enfoques interesantes. Por ejemplo, bastantes especialistas —entre los cuales David ocupa un lugar destacado- subrayan la dependencia de la trayectoria pasada en los procesos de cambio técnico. La parábola del teclado QWERTY que contaba David (1986) sirve de brillante ilustración a esta hipótesis. De acuerdo con ella, el desarrollo de técnicas particulares sigue su camino propio, en el cual los acontecimientos pasados se unen a la lista de determinantes de los acontecimientos futuros. El mecanismo puede funcionar para bien -es decir, creando círculos virtuosos que den lugar a progreso técnico cada vez más rápido- o para mal —encerrando a este último en trayectorias subóptimas que constituyen callejones sin salida-. Esto último sucede cuando la dirección adoptada por el cambio técnico implica el abandono de otras direcciones, que a posteriori resultan más fructíferas. A la vista de hipótesis como ésta, uno se pregunta si otras respuestas al problema de la contribución económica de determinadas innovaciones, dadas en el pasado por los cliómetras e inspiradas en el análisis estático, eran tan acertadas como parecían. 
El progreso técnico proporciona un paradigma con vistas al análisis de otros procesos dinámicos, como pueda ser el del cambio institucional. La aparentemente probada dependencia de trayectoria del primero nos lleva a pensar en un fenómeno semejante por lo que respecta al segundo, o en modelos más ricos que incluyan a ambos. Falta por ver, sin embargo, en qué casos los procesos dependientes de la trayectoria demostrarán poseer un poder explicativo superior al de los modelos más familiares, con variables exógenas y endógenas y causalidad unidireccional ${ }^{15}$. El nuevo paradigma tiene sus paralelos en ciencia y en estadística. Algunos analistas del cambio técnico, como Robert Nelson y Sidney Winter (1982), llevan tiempo postulando un acercamiento de la economía a la biología evolucionista, en vez de a la física mecánica. Mientras que la segunda ha inspirado el análisis estático que predomina en la corriente principal de la economía, la primera les parece a estos autores más adecuada para el estudio de procesos evolutivos. Así, técnicas concretas o categorías más amplias del campo de la tecnnología aparecen como el equivalente de especies vivientes, que pueden multiplicarse, evolucionar, estancarse o desaparecer por completo, dependiendo de las condiciones de un medio que ellas mismas ayudan a configurar. En cuanto a los aspectos formales del nuevo paradigma, Brian Arthur y Paul David han insistido repetidamente en la idoneidad de ciertos procesos estocásticos para modelizar las trayectorias evolutivas. Aparte de David, algunos historiadores económicos como Joel Mokyr (1990 y 1991) o G. N. von Tulzelmann (1997) parecen encariñados con la idea; no obstante, hasta donde conozco, solamente David (1993) entre los historiadores económicos ha emprendido la tarea de modelizar formalmente procesos dependientes de la trayectoria ${ }^{16}$.

Finalmente, hay otras corrientes en economía en las cuales también pueden pescar los historiadores económicos. La economía del bienestar conecta bien con la preocupación de los historiadores económicos por la evolución de las condiciones de vida en el muy largo plazo: de hecho, la moderna demografía histórica y la antropometría histórica deben algo a los avances registrados en esa disciplina. La economía del medio ambiente también participa de esa preocupación por el muy largo plazo que es característica de la Historia. Algunas construcciones teóricas nuevas, como pueda ser el concepto de racionalidad limitada de Herbert Simon, parecen muy

${ }^{15}$ Sobre este punto, véase Landes (1994).

${ }^{16}$ Los historiadores económicos de la antigua Unión Soviética podrían estar mejor equipados para ello que sus colegas occidentales. Véase como ejemplo Borodkin y Svischov (1992). 
prometedoras en su aplicación al largo plazo, y lo mismo sucede con otros casos. En todos ellos, no se trata tanto de que los historiadores económicos vuelvan a tomar prestadas construcciones completas acabadas por otras disciplinas, como ha podido suceder en el pasado, sino de que la historia económica preste su cooperación activa a proyectos en curso.

\section{CONSIDERACIONES FINALES}

Creo que ya va siendo hora de hacer inventario y extraer algunas conclusiones. Desde finales de los años cincuenta, la historia económica $-\mathrm{y}$ con ella la Historia en general- se ha beneficiado del empleo del razonamiento económico y de las técnicas cuantitativas. Hasta aquí bien, y el filón no está ni mucho menos agotado. Sin embargo, un número creciente de historiadores económicos tiene la sensación de que esta dependencia de herramientas diseñadas para el tratamiento de cuestiones del corto plazo está limitando nuestra capacidad para enfrentarnos con problemas del largo plazo. La teoría económica standard supone un estado del mundo en el cual la mayor parte de las variables se mantiene constante a corto plazo, de manera que sólo hay que preocuparse por unas pocas, y (a menudo) por relaciones de causa-efecto en un único sentido. Al mismo tiempo, si los historiadores económicos se contentan con imitar los actos de los economistas, es improbable que puedan pagar nunca sus deudas para con estos últimos y hacer una aportación significativa en el otro sentido. Bien miradas, las razones del desasosiego de los historiadores económicos resul$\tan$ muy comprensibles.

En la actualidad, los vigías de la historia económica escudriñan el horizonte de las corrientes laterales de la economía en busca de nuevos caminos. En la sección anterior he podido parecer, quizá, demasiado entusiasta en relación con estas nuevas posibilidades, por lo cual éste es el lugar adecuado para hacer matizaciones. Dicho brevemente, estoy a favor de financiar la exploración de la terra incognita, pero no de enviar grandes ejércitos a su conquista. Por lo demás, resulta demasiado fácil soñar con magnos procesos dependientes de la trayectoria, en los cuales las técnicas productivas, las instituciones, etcétera, se configuren y reconfiguren modelizando el curso real de la Historia. Ese modelo gigante podría constituir un nuevo materialismo histórico, si bien asentado sobre bases más sólidas: esto es, atribuyendo racionalidad (limitada) y búsqueda de la propia utilidad a los individuos, antes que a esos entes llamados clases sociales, y sin otorgar 
a priori a ciertas variables el papel de determinantes en última instancia. Sin embargo, las construcciones de este tipo de momento sólo pueden tener un carácter especulativo, toda vez que la complejidad de tal modelo hace imposible - y lo hará por mucho tiempo- cualquier intento de formalización y contrastación rigurosa. Lo cual no significa que tales construcciones sean inútiles: en cierto sentido, ésta es la tarea emprendida por Douglass North, o lo sería si este autor dejara de insistir en la influencia unilateral de las instituciones sobre los resultados económicos. No obstante, uno de los logros de la cliometría ha sido el avance en la formalización y contrastación de sus modelos, y no creo que debamos renunciar al mismo. En este terreno, otra tara heredada de nuestra ascendencia económica, que tendremos que aprender a superar, es nuestra falta de familiaridad con aquellas técnicas estadísticas adecuadas para modelar los procesos dependientes de trayectoria: los historiadores económicos podemos hablar de procesos de Markov, cadenas de Markov y similares, pero hasta que no dominemos realmente su mecánica no podremos decir nada serio acerca de sus posibilidades reales ${ }^{17}$. Entre tanto, la fe en la ciencia no pasará de ser un mal sustituto del método científico.

Hasta donde alcanzo a ver, las avanzadillas del ejército de los historiadores económicos empezarán a explorar por su propia cuenta las nuevas tierras. Unidades más grandes seguirán transitando por los caminos, más conocidos, abiertos por el análisis económico standard y por las herramientas estadísticas convencionales, y la retaguardia se moverá, quizá, unos pocos pasos en esa dirección. En conjunto, no creo que el centro de gravedad se desplace mucho durante las próximas décadas. Sin embargo, la historia económica me recuerda a un puesto comercial avanzado, en el que se ofrecen a la Historia productos de manufactura Econ. Con el paso del tiempo, algunos puestos comerciales han dado origen a grandes ciudades, que se han convertido en capitales o, por lo menos, en centros importantes de imperios comerciales. Situada en el territorio del largo plazo, en el que confluyen las rutas de todas las ciencias suciales, y en posesión de sólidas relaciones con la que parece ser la más avanzada entre ellas, la historia económica parece a primera vista capaz de convertirse en uno de esos centros. Ahora bien, esta posibilidad no está al alcance de la mano; se vislumbra en un futuro lejano, y su realización depende de muchos

" Como autor de un manual de estadística para historiadores recientemente publicado, tengo que entonar el mea culpa, ya que el libro introduce en las técnicas habituales de determinación unilateral, sin apenas referencia a modelos estocásticos complejos. Lo único que puedo decir en mi descargo es que estos últimos no son para principiantes. 
factores. Entre ellos, del esfuerzo y la imaginación que desplieguen los historiadores económicos, así como de su capacidad para cruzar por encima de las fronteras: aquellas que separan, unas de otras, a las distintas disciplinas constituyen el primer obstáculo a superar en el camino de quienes aspiren a ensanchar las fronteras generales del conocimiento científico.

\section{BIBLIOGRAFIA}

Allen, Bobert C. (1997): «Agriculture and the Origins of the State in Ancient Egipt», Explorations in Economic History, 34, núm. 2, pp. 135-154.

Arrow, Kenneth J. (1986): «History: the View from Economics», en PARKER (ed.), pp. 13-20.

ArThUR, W. Brian (1989): «Competing Technologies, Ingreasing Returns and Lock-in by Historical Events», Economic Journal, 99, núm. 1, pp. 116-131. Arthur, W. B.; Ermoliev, Y. M., y Kaniovski, Y. M. (1987): «Path.Dependent Processes and the Emergence of Macro-Structure», European Journal of Operational Research, 30, pp. 294-303.

Barro, Robert J. (1991): «Economic Growth in a Cross Section of Countries», Quarterly Journal of Economics, 106, núm. 2, pp. 407-443.

BorodkIN, Leonid, y Svischov, Mijail (1992): «El sector privado de la economía soviética en los años veinte: modelado de los procesos sociales», Revista de Historia Económica, X, núm. 2, pp. 241-262.

Carlos, Ann, y LewIs, Frank (1995): «Property Rights, Competition and Depletion in the Eighteenth-Century Canadian Fur Trade: The Role of the European Market», mimeo.

Carneiro, R. (1970): «A Theory of the Origin of the State», Science, 169, pp. $733-738$.

ColL, Sebastián (1990): «La Nueva Historia Económica y su Influencia en España», en RuEDA, Germán (ed.), Doce Estudios de Historiografia Contemporánea, Santander, Universidad de Cantabria/Asamblea Regional de Cantabria, pp. 69-119.

Coll, Sebastián, y Guijarro, Marta (1999): Estadística Aplicada a la Historia y a las Ciencias Sociales, Madrid, Pirámide.

Coll, Sebastián, y Gutierrez Bringas, Miguel A. (1995): «Estimating Production Figures from Price Data. An Application to the Case of 19th-Century Spanish Agricultural Production», Universidad de Cantabria, Departamento de Economía, Documento de Trabajo núm. 9506.

- (1998): «A Supply-Side Method for Output Estimation. Application to 19th-Century Spanish Agricultural Production», Ponencia presentada al XII Congreso Internacional de Historia Económica, Madrid, 24-28 de agosto de 1998, Sesion C54, «Production et Productivité Agricoles dans le Monde Occidental $\left(\mathrm{XIX}^{-}-\mathrm{XX}^{\mathrm{c}}\right.$ siècles)».

ConRad, Alfred, y MeYER, John R. (1958): «'The Economics of Slavery in Ante-Bellum South», Joumal of Political Economy, 66, pp. 95-130. 
Crafts, N. F. R. (1985): British Economic Growth During the Industrial Revolution, Oxford, Clarendon Press.

- (1987): «Cliometrics, 1971-1986: A Survey», Joumal of Applied Econometrics, 2, pp. 171-192.

DAvid, Paul A. (1986): «Understanding the Economics of QWERTY: the Necessity of History», en PARKer (ed.), pp. 30-49.

- (1993): «Path-Dependence and Predictability in Dynamic Systems with Local Network Externalities: A Paradigm for Historical Economics», en ForaY, D., y Freeman, C. (eds.), Technology and the Wealth of Nations, Londres y Nueva York, Pinter Publishers, pp. 208-231.

Dudley, Leonard M. (1990): «Structural Change in Interdependent Bureaucracies: Was Rome's Failure Economic or Military?», Explorations in Economic History, 27, núm. 2, pp. 232-248.

- (1991) The Word and the Sword. How Techniques of Information and Violence Have Shaped our World, Oxford, Blackwell.

DumkE, Rolf H. (1992): «The Future of Cliometric History - A European View», Scandinavian Economic History Review, 40, núm. 3, pp. 3-28.

EgGERTSSON, Thráinn (1990): Economic Bebaviour and Institutions, Cambridge, Cambridge University Press. Traducción española (1995): El comportamiento económico y las instituciones, Madrid, Alianza.

FEENY, David (1987): «The Exploration of Economic Change: The Contribution of Economic History to Development Economics», en FIELD, A. J. (ed.), pp. $91-119$.

FIELD, Alexander J. (1980): «The Problem with Neoclassical Institutional Economics: A Critique with Special Reference to the North/Thomas Model of pre-1500 Europe», Explorations in Economic History, 18, pp. 174-198.

- (1987): «The Future of Economic History», en FIELD, A. J. (ed.), pp. 1-41.

FIELD, Alexander J. (ed.) (1987): The Future of Economic History, Boston, Kluwer Nijhoff Publishing.

FISHLOW, Albert A., y FOGEL, Robert W. (1971): «Quantitative Economic History: An Interim Evaluation; Past, Trends and Present Tendencies», Journal of Economic History, 21, núm. 1, pp. 15-42.

FOGEL, Robert W. (1965): «The Reunification of Economic History with Economic Theory», American Economic Review, 55, núm. 2, pp. 92-98.

- (1975): «The Limits of Quantitative Methods in History», American Historical Review, 80, núm. 2, pp. 329-350.

- (1992): «Second Thoughts on the European Escape from Hunger: Famines, Chronic Malnutrition, and Mortality», en Osmani, S. R. (ed.), Nutrition and Poverty, Oxford, Oxford University Press, pp. 243-286.

Fogel, Robert W., y Elton, G. R. (1983): Which Road to the Past? Two Views of History, New Haven, Yale University Press.

Fogel, Robert W., y Engerman, Stanley G. (1974): Time on the Cross: The Economics of American Negro Slavery, Boston, Little Brown.

Friedman, Milton (1953): «The Methodology of Positive Economics», en Essays an Positive Economics, Chicago, University of Chicago Press. Traducción espanola (1967): «La metodología de la economía positiva», en Ensayos sobre eco nomia positiva, Madrid, Gredos, pp. 9-44. 
Fuentes Quintana, Enrique (ed.) (2000) Raices bistóricas de los problemas de la economía actual. El legado del modelo castizo de desarrollo económico, Madrid.

GutiERrez Bringas, Miguel A. (1998): «La Producción y la Productividad de los Factores en la Agricultura Española, 1753-1935», Tesis Doctoral, Universidad de Cantabria.

- (2000): La productividad de los factores en la agricultura española, 1752-1935, Madrid, Banco de España.

Hatton, T. J., y Williamson, J. G. (1998): The Age of Mass Migration. Causes and Economic Impact, Oxford.

Harley, C. Knick (1988): «Ocean Freight Rates and Productivity, 1740-1913: The Primacy of Mechanical Invention Reaffirmed», Joumal of Economic History, 48, núm. 4, pp. 851-876.

Hoffman, Philip T. (1991): «Land Rents and Agricultural Productivity», Journal of Economic History, 51, núm. 4, pp. 772-805.

Hughes, J. R. T. (1971): «Is New Economic History an Export Product?», en McCloskey, D. N. (ed.), Essays on a Mature Economy: Britain after 1840, Princeton, Princeton University Press.

JONES, E. L. (1990): «Economics in the History», Journal of Interdisciplinary Economics, 3, pp. 157-172.

Jorgenson, Dale (1966): «The Embodiment Hypothesis», Journal of Political Economy, 74, núm. 1, pp. 1-17.

Kremer, Michael (1993): «Population Growth and Technological Change: One Million B.C. to 1990», Quarterly Joumal of Economics, 108, núm. 3, pp. 681-716.

LANDES, David (1994): «What Room for Accident in History?: Explaining Big Changes by Small Events», Economic History Review, 47, núm. 4, pp. 637-656.

Leilonhufvud, Axel (1973): «Live among the Econ», Western Economic Journal, 11, núm. 3, pp. 327-337. Traducción española (1982): «La vida entre los Econos», Información Comercial Española, 590, pp. 63-68.

McCloskey, D. N. (1973): Economic Maturity and Entrepreneurial Decline: British Iron and Steel, 1870-1913, Cambridge, Cambridge University Press.

- (1978): «The Achievements of the Cliometric School», Journal of Economic History, 36, núm. 1, pp. 13-28.

- (1981): «The Industrial Revolution: A Survey», en Floud, R. D., y MCCloskey, D. N. (eds.), The Economic History of Britain since 1700, Cambridge, Cambridge University Press, vol. I, pp. 103-127.

- (1986): «Why Economic Historians Should Stop Relying on Statistical Tests of Significance, and Lead Economists and Historians into the Promised Land», Newsletter of the Cliometric Society, 2, núm. 2, pp. 5-7.

- (1987): Econometric History, Londres, MacMillan.

MокYR, Joel (1990): The Lever of Richess. Technological Creativity and Economic Progress, Oxford, Oxford University Press. Traducción española (1993): La palanca de la riqueza. Creatividad tecnológica y progreso económico, Madrid, Alianza.

- (1991): «Evolutionary Biology, Technical Change and Economic History», Bulletin of Economic Research, 43, núm. 2, pp. 127-149. 
Nelson, Robert R., y WInter, Sidney G. (1982): An Evolutionary Theory of Economic Change, Cambridge, MA., Harvard University Press.

NoRTH, Douglass C. (1968): «Sources of Productivity Change in Ocean Shipping, 1600-1850», Joumal of Political Economy, 66, pp. 953-970.

- (1974): «Beyond the New Economic History», Joumal of Economic History, 34, núm. 1, pp. 1-7.

- (1981): Structure and Change in Economic History, Nueva York, W. W. Norton \& Co. Traducción española (1984): Estructura y cambio en la bistoria económica, Madrid, Alianza.

- (1984): «Government and the Cost of Exchange in History», Journal of Economic History, 44, núm. 2, pp. 255-264.

- (1986): «Is It Worth Making Sense of Marx?», Inquiry, 29, pp. 57-63.

- (1989): «Institutions and Economic Growth: An Historical Introduction», World Development, 17, núm. 9, pp. 1319-1332.

- (1990): Institutions, Institutional Change and Economic Performance, Cambridge, Cambridge University Press.

NorTh, Douglass C., y Thomas, Robert P. (1973): The Rise of the Western World. A New Economic History, Cambridge, Cambridge University Press. Traducción española (1978): El nacimiento del mundo occidental. Una nueva bistoria económica (900-1700), Madrid, Siglo XXI.

PARKER, William N. (ed.) (1986): Economic History and the Modern Economist, Oxford, Basil Blackwell.

Prados de la Escosura, Leandro (1988): De imperio a Nación. Crecimiento y Atraso Económico en España (1780-1930), Madrid, Alianza Editorial.

- (1995): «Spain's Gross Domestic Product, 1850-1993: Quantitative Conjectures», Madrid, Universidad Carlos III.

RedulCH, Fritz (1965): «New and Traditional Approaches to Economic History and their Interdependence», Joumal of Economic History, 25, pp. 480-495.

ReHER, David (2000): «Mercado de trabajo y empleo en España durante el siglo actual: perspectivas nuevas sobre un tema tradicional», en FUENTES QUINTANA (ed.).

RoSENBERG, Nathan (1982): Inside the Black Box, Cambridge, Cambridge University Press.

- (1994): Exploring the Black Box: Technology, Economics and History, Cambridge, Cambridge University Press.

Schmookler, Jacob (1966): Invention and Economic Growth, Cambridge, MA., Harvard University Press.

Schumpeter, Joseph A. (1942): Capitalism, Socialism and Democracy, Nueva York, McGraw-Hill. Traducción española (1984): Capitalismo, socialismo y democracia, Barcelona, Folio.

Simon, Herbert A. (1984): «On the Behavioral and Rational Foundations of Economic Dynamics», Journal of Economic Bebavior and Organization, 5, pp. 35-55.

Simon, Herbert A.; EgIDI, M.; HaRris, R., y Viale, R. (1992): Economics, Bounded Rationality and the Cognitive Revolutions, Aldershot, Edward Elgar.

Simpson, James (1989): «La Producción Agraria y el Consumo Español en el Siglo XIX», Revista de Historia Económica, 7, núm. 2, pp. 355-388. 
Solow, Robert E. (1986): «Economics: Is Something Missing?», en PARKER, William N. (ed.), pp. 21-29.

Tilly, Charles; Tilly, Louise A., y Tilly, Richard (1991): «European Economic and Social History in the 1990s", Journal of European Economic History, 20, núm. 3, pp. 645-671.

Tunzelmann, G. N. von (1997): Technology and Industrial Progress. The Foundations of Economic Growth, Cheltenham, Edward Elgar.

WHAPLES, Robert (1991): «A Quantitative History of the Journal of Economic History and the Cliometric Revolution», Joumal of Economic History, 51, núm. 2, pp. 289-301.

WHITE, Lynn (1962): Medieval Technology and Social Change, Oxford, Oxford University Press. Traducción española (1990): Tecnologia medieval y cambio social, Barcelona, Paidós.

Williamson, J. G. (1997): Industrialization, Inequality and Economic Growth, Cheltenham, Edward Elgar.

- (1998): «Growth, Distribution, and Demography: Some Lessons from History», Explorations in Economic History, 35, núm. 3, pp. 241-271.

Yasuba, Kasukichi (1961): «The Profitability and Viability of Plantation Slavery in the United States», Economic Studies Quarterly, 12, pp. 60-67. 